\title{
Comparing the effects of China's three basic health insurance schemes on the equity of health-related quality of life: using the method of coarsened exact matching
}

\author{
Min Su${ }^{1}$, Zhongliang Zhou ${ }^{1 *}$, Yafei $\mathrm{Si}^{1}$, Xiaolin Wei ${ }^{2}$, Yongjian Xu' ${ }^{1}$, Xiaojing Fan ${ }^{3}$ and Gang Chen ${ }^{4}$
}

\begin{abstract}
Background: China has three basic health insurance schemes: Urban Employee Basic Medical Insurance (UEBMI), Urban Resident Basic Medical Insurance (URBMI) and New Rural Cooperative Medical Scheme (NRCMS). This study aimed to compare the equity of health-related quality of life (HRQOL) of residents under any two of the schemes.

Methods: Using data from the 5th National Health Services Survey of Shaanxi Province, China, coarsened exact matching method was employed to control confounding factors. We included a matched sample of 6802 respondents between UEBMI and URBMI, 34,169 respondents between UEBMI and NRCMS, and 36,928 respondents between URBMI and NRCMS. HRQOL was measured by EQ-5D-3L based on the Chinese-specific value set. Concentration index was adopted to assess health inequality and was decomposed into its contributing factors to explain health inequality.

Results: After matching, the horizontal inequity indexes were 0.0036 and 0.0045 in UEBMI and URBMI, 0.0035 and 0 . 0058 in UEBMI and NRCMS, and 0.0053 and 0.0052 in URBMI and NRCMS respectively, which were mainly explained by age, educational and economic statuses. The findings demonstrated the pro-rich health inequity was much higher for the rural scheme than that for the urban ones.

Conclusion: This study highlights the need to consolidate all three schemes by administrating uniformly, merging funds pooling and benefit packages. Based on the contributing factors, strategies aim to facilitate health conditions of the elderly, narrow economic gap, and reduce educational inequity, are essential. This study will provide evidence-based strategies on consolidating the fragmented health schemes towards reducing health inequity in both China and other developing countries.
\end{abstract}

Keywords: China, Basic health insurance schemes, Health-related quality of life, Coarsened exact matching, Income-related health equity, Decomposition

\section{Background}

Health equity has long been regarded as an overarching objective pursued by the whole health systems [1]. The evidence from previous research suggested that health insurance which designed to improve health care access could reduce health inequity $[2,3]$. Therefore, China has implemented a

\footnotetext{
* Correspondence: zzliang1981@163.com

${ }^{1}$ School of Public Policy and Administration, Xi'an Jiaotong University, Xi'an, China

Full list of author information is available at the end of the article
}

series of comprehensive reforms to develop health insurance schemes $[2,4,5]$. There are three basic health insurance schemes in China. Urban Employee Basic Medical Insurance (UEBMI), a compulsory scheme, was established for the urban residents who work in the formal at the end of 1998. UEBMI is financed by payroll taxes from employers (6\%) and employees $(2 \%)[6,7]$. The inpatient care is covered by a pooled fund and outpatient care is supported by Individual Account [6,7]. By the end of 2013, there were approximately 274.16 million people 
enrolled in the UEBMI, constituting $37.50 \%$ of the total urban residents. Urban Resident Basic Medical Insurance (URBMI), a voluntary scheme, was piloted in 2007 for the rest urban residents without formal jobs or unemployed such as children, students, elderly, and the young unemployed. URBMI has a Social Pooling Account for inpatient care and a Household Account for critical outpatient care (e.g. chronic or fatal disease). Financing is from the insured residents and local government. In 2013, the average per capital financing support of URBMI was RMB 380 (US\$ 61.29), among which the insured resident was responsible for RMB 120(US\$19.35) [8]. By the end of 2013, there were approximately 299.06 million people enrolled in the URBMI, accounting for $40.90 \%$ for the total urban people respectively. Additionally, New Rural Cooperative Medical Scheme (NRCMS), a voluntary scheme, was piloted in 2003 for the rural areas. NRCMS also has a Social Pooling Account and Household Account [9-11]. In 2013, the average per capital financing support of NRCMS was RMB 370 (US\$ 59.68), among which the participant was responsible for RMB 90 (US\$14.52) [8]. By the end of 2013, there were 0.80 billion people (accounting for $98.70 \%$ for the total rural people) enrolled in the NRCMS [8].

However, fragmentation in basic health insurance schemes is a significant factor for inequitable access to health care and financial protection for population covered by different insurance schemes in China [11]. Fragmentation means that there are a great number of separate funding mechanisms (e.g. many small insurance schemes) and a wide range of healthcare providers paid from different funding pools [12, 13]. In China, the administration, pooling levels and benefit packages are quite different across different schemes (Table 1), which result in the fragmented health insurance schemes. Specifically, NRCMS is administrated by the Chinese National Health and Family Planning Commission, while UEBMI and URBMI are administrated by the Chinese Ministry of Human Resources and Social Security. In terms of the funding pool, NRCMS is pooled at county level, while UEBMI and URBMI are pooled at municipal level. There are approximately 2856 counties and 333 municipalities in China, which indicates that there are about 2856 NRCMS schemes, 333 UEBMI schemes and 333 URBMI schemes in China. Third, reimbursement rate was $10 \%$ lower and healthcare coverage was much smaller for NRCMS than that for UEBMI and URBMI [11, 14, 15]. Fragmentation in basic health insurance schemes may have negative effects on health equity to some extent $[11,4]$. Therefore, establishing a consolidated health insurance scheme by 2020 is one of the crucial objectives of the whole health system reforms in China (both vertical consolidation and horizontal consolidation). For vertical consolidation, the fund pooling and management of NCMS (from county level) and UEBMI and URBMI (from municipal level) should be moved to provincial and then country levels. For horizontal consolidation, the funding pools, management offices and information systems of three basic health insurance schemes should be merged together to reduce human resources costs [11-13]. Experience across the world demonstrates that consolidation of health insurance schemes has a multitude of benefits $[6,14,15]$. For example, consolidating the fragmented schemes, in theory, could extend financial pools, promote the efficiency in administration, narrow the inequities in benefit package and improve the access of health care, thereby reducing health inequity to some extent. So Chinese government has formulated a national guideline in 2016 to guide the consolidation of the existing fragmented schemes.

Recent decades have witnessed a wide range of research projects providing worthy insights into the effects of health insurance schemes on population health. The evidence showed that observational studies, natural experiments and experimental studies have been conducted to investigate the relationship between health insurance and health. Apart from this, both objective (e.g. mortality, birth weight, blood pressure) and subjective (e.g. selfreported health, health-related quality of life) health outcome measures have been used to explore the impacts of health insurance schemes on population health. Based on the literature review [16, 17], convincing evidence indicated that basic health insurance schemes can improve the health of vulnerable subgroups, such as elderly people, children and other individuals with specific health problems, especially those with low income. The related research in China reached similar conclusions. For example, an often-voiced opinion was that the health of the insured rural residents has been improved greatly since the establishment of NRCMS [11]. By using the EQ-5D instrument, Wang et al. [18] found the pilot of Rural Mutual Health Care (RMHC), which could be regarded as one type of the NRCMS, has led to decreases in pain or discomfort, and anxiety or depression for the insured, and shown positive impacts on mobility and usual activity for the elderly. Based on the URBMI survey conducted from 2007 to 2010, Pan et al. found URBMI was associated with better self-reported health $[19,20]$. However, few evidence also indicated that the health condition of the insured was not improved significantly $[21,22]$. In addition, few studies were available to compare the potential effects of different health insurance schemes on health equity. 
Table 1 Summary of basic health insurance schemes in China in 2013

\begin{tabular}{|c|c|c|c|}
\hline & UEBMI & URBMI & NRCMS \\
\hline \multicolumn{4}{|l|}{ Basic information } \\
\hline Year of launch & 1999 & 2007 & 2003 \\
\hline Target population & Urban employees in formal sectors & $\begin{array}{l}\text { Urban residents without formal jobs or } \\
\text { unemployed: children, students, elderly } \\
\text { people }\end{array}$ & Rural residents \\
\hline Enrolment type & Compulsory & Voluntary & Voluntary \\
\hline Enrolment (n, \%) & 274.16million (37.50\%) & 299.06 million (40.90\%) & 0.80 billion (98.70\%) \\
\hline Administration & $\begin{array}{l}\text { Chinese Ministry of Human Resources } \\
\text { and Social Security }\end{array}$ & $\begin{array}{l}\text { Chinese Ministry of Human Resources } \\
\text { and Social Security }\end{array}$ & $\begin{array}{l}\text { Chinese National Health and Family Planning } \\
\text { Commission }\end{array}$ \\
\hline Risk-pooling units & $\begin{array}{l}\text { Municipal level, } \\
2856 \text { Risk-pooling units }\end{array}$ & $\begin{array}{l}\text { Municipal level, } \\
333 \text { Risk-pooling units }\end{array}$ & $\begin{array}{l}\text { County level, } \\
333 \text { Risk-pooling units }\end{array}$ \\
\hline \multicolumn{4}{|l|}{ Benefit packages } \\
\hline Service coverage & $\begin{array}{l}\text { A Social Pooling Account for } \\
\text { inpatient care and an Individual } \\
\text { Account for outpatient care } \\
\text { (generous) }\end{array}$ & $\begin{array}{l}\text { A Social Pooling Account for inpatient } \\
\text { care and a Household Account for } \\
\text { critical outpatient care (i.e. chronic or } \\
\text { fatal disease) (limited) }\end{array}$ & $\begin{array}{l}\text { NRCMS included a Social Pooling Account } \\
\text { for inpatient care and a Household Account } \\
\text { for critical outpatient care (i.e. chronic or fatal } \\
\text { disease) (limited) }\end{array}$ \\
\hline $\begin{array}{l}\text { Total premium per } \\
\text { person }\end{array}$ & - & RMB 380(US\$61.29) & RMB370(US\$59.68) \\
\hline $\begin{array}{l}\text { Government } \\
\text { subsidy per } \\
\text { person }\end{array}$ & 0 & RMB 260(US\$41.94) & RMB 280(US\$45.16) \\
\hline $\begin{array}{l}\text { Individual } \\
\text { contribution }\end{array}$ & $2-3 \%$ of salary & RMB 120(US\$19.35) & RMB 90(US\$14.52) \\
\hline $\begin{array}{l}\text { Employer } \\
\text { contribution }\end{array}$ & $6-8 \%$ of salary & 0 & 0 \\
\hline $\begin{array}{l}\text { Actual } \\
\text { reimbursement ratio } \\
\text { (Inpatient care) }\end{array}$ & $68.8 \%$ & $53.62 \%$ & $50.15 \%$ \\
\hline
\end{tabular}

Data resource: National Health Statistics Annual Report and Qingyue Meng et al., [11]

This study aimed to fill the gap by comparing the income-related inequity in health-related quality of life (HRQoL) of the insured residents with different health insurances: between UEBMI and URBMI, UEBMI and NRCMS, and URBMI and NRCMS respectively. There are two key strengths in general. Firstly, we estimated the effects of the three basic health insurance schemes in China on the incomerelated inequity of HRQoL based on the coarsened exact matching (CEM) method to guarantee better balance of empirical distributions of the covariates between the comparison groups [23, 24]. Secondly, HRQoL, scored by the EQ-5D-3L instrument based upon the preferences of the Chinese general population, was employed as a health outcome measure [25]. Although, HRQoL has long been extensively applied in the research of health inequity in international literature across the world [26, 27], it was the first time to compare the effects of UEBMI, URBMI and NRCMS on the income-related inequity of HRQoL using the CEM method.

\section{Methods \\ Data}

Data were derived from the 5th National Health Services Survey (NHSS) of Shaanxi Province, Western China, in 2013. The NHSS has been initiated and conducted by the National Health and Family Planning Commission of China every 5 years since 1993 [28]. Shaanxi Province is situated in the northwest of China. There were roughly 37.60 million population living in the area with more than $205,800 \mathrm{~km}^{2}$, among which $48.70 \%$ of residents were living in rural areas. By the end of 2013, the per capital Gross Regional Product (GRP) was RMB 43,117 (US\$ 6954, US\$ were obtained by the annual average exchange rate US $\$ 1=$ RMB 6.20 in 2013), which was lower than the per capita Gross Domestic product (GDP) of China (RMB 43,852, US\$ 7072) [8].

By using a face-to-face interview combined with a standardized questionnaire which consisted of basic information concerning each respondent's demographic as well as socio-economic characteristics, health conditions measured by the EQ-5D-3L instrument and self-reported illness and chronic disease; health insurance characteristics 
and health service utilizations. Additionally, there are three questions to get the information about health insurance characteristics: 1) Do you have health insurance; and 2) Which type of health insurance do you have; and 3) Do you buy any supplementary health insurance? By using the four-stage, stratified, random sampling method, 32 counties or districts of Shaanxi Province were selected randomly in the first stage, and 160 townships or streets were selected in the next stage. Thirdly, 320 villages or communities were chosen. Finally, 20,700 households $(57,529$ people) were interviewed. Since this study mainly focuses on the respondents aged 15 years and older, 5079, 2443 and 37,877 respondents covered by UEBMI, URBMI and NRCMS respectively were identified in the final sample for further analysis after data cleaning.

\section{Health-related quality of life}

The EQ-5D-3L, with 245 kinds of health statuses, is the most widely used instrument to measure HRQoL based on people's preferences across the world [29]. There are five dimensions (e.g. mobility, self-care, usual activities, pain or discomfort and anxiety or depression) and three response levels (e.g. no problems, some problems and extreme problems) for each dimension [30]. Over the past few decades, the utilization of the EQ-5D-3L was confined in China as the lack of Chinese value set. In our research, a tariff of Chinese people's preferences based on the time trade-off method, which ranges from -0.149 to 1 ( -0.149 stands for death and 0 stands for full health), was employed to measure the HRQoL [25].

\section{Coarsened exact matching method}

It is more likely to neglect other potential confounding influences of different comparison groups that may result in health inequity [31] by roughly comparing the income-related inequity of HRQoL between different health insurance schemes. Therefore, we applied the coarsened exact matching (CEM) method, firstly proposed by Lacus, et al. [23, 24] to keep better balance of distributions of the covariates between the comparison groups and thereby reducing the biases. In general, the basic algorithm of CEM mainly includes three procedures. Firstly, each variable is coarsened by recoding to group and appoint the indistinguishable values with the same value. In the second step, the algorithm of exact matching is employed. And then removing the coarsened data, the final matched data should be reserved $[23,24]$. A weighting variable generated by CEM method is used to equalize the number of observations within comparison groups [23, 24]. For balance checking, multivariate imbalance measure $\mathrm{L}_{1}$ was used and it was a relative magnitude depending on the data and the selected covariates [23, 24]. $\mathrm{L}_{1}$ ranges from 0 (perfect global balance) to 1 (maximal imbalance) and larger value represents larger imbalance between comparison groups. A good matching performance would bring a substantial reduction in $\mathrm{L}_{1}[23,24] . \mathrm{L}_{1}$ can be calculated as follows: Firstly, covariates were coarsened into bins. And then the discretized variables were cross-tabulated as $\mathrm{X}_{1} \times$ $\ldots \ldots \times X_{k}$ for the treated and the control groups separately, and recorded the $\mathrm{k}$-dimensional relative frequencies for the treated and $f_{\varepsilon_{1} \ldots \ldots \varepsilon_{k}}$ for the control $g_{\varepsilon_{1} \ldots \ldots \varepsilon_{k}}$ units. Finally, the measure of imbalance is the absolute difference over all the cell values [24].

$$
L_{1(f, g)}=\frac{1}{2} \sum_{\varepsilon_{1} \ldots \ldots \varepsilon_{k}}\left|f_{\varepsilon_{1} \ldots \ldots \varepsilon_{k}}-g_{\varepsilon_{1} \ldots \ldots \varepsilon_{k}}\right|
$$

More details of the CEM method can be found in other literature [23, 24, 32, 33]. The CEM method was modeled by using the cem command code.

\section{Health inequity \\ Concentration index}

Concentration index $(\mathrm{CI})$ was applied to quantify the income-related inequality in HRQoL [34-36]. CI ranges from -1 to 1 , and 0 represents no income-related inequality of HRQoL $[37,38]$. The positive score of CI shows pro-rich inequality of HRQoL and the negative score of CI shows pro-poor inequality in HRQoL. The Eq.2 was used to calculate the CI:

$$
\mathrm{C}=\frac{2}{\mu} \operatorname{cov}(y, r)
$$

where $\mathrm{C}$ represents concentration index, $y$ represents HRQoL, $\mu$ represents the mean of overall EQ-5D utility value, $\gamma$ represents the fractional rank of income distribution $[39,40]$.

\section{Decomposition methods of the $\mathrm{Cl}$}

The income-related inequality in HRQoL could be explained by decomposing the $\mathrm{CI}$ into its contributing factors based on a regression, using Eqs. 3 and 4 [41].

$$
y_{i}=\alpha+\sum_{j} \beta_{j}^{m} x_{j i}+\sum_{k} r_{k}^{n} z_{k i}+\varepsilon_{i}
$$

where $y_{i}$ represents EQ-5D utility value; $\mathrm{X}$ represents the unavoidable determinants of HRQoL (gender and age); $\mathrm{z}$ represents the avoidable determinants of HRQoL (marital states, educational states, commercial insurance and annual personal expenditure); $\beta_{j}^{m}$ and $r_{k}^{n}$ are marginal effects of each variable; $\varepsilon i$ stands for the error. The decomposition of the concentration index $\mathrm{C}$ could be defined as: 


$$
\mathrm{C}=\sum_{j}\left(\beta_{j}^{m \overline{x_{j}}} /{ }_{\mu}\right) C_{j}+G C_{\varepsilon} /_{\mu}
$$

Where $\mu$ is the mean of $y, C_{j}$ are the CI for $x j$ and $\overline{x_{j}}$ are the means of $x_{j}$. The contributions of independent variables are showed by the first item on the right side of Eq. 3 to the inequality of HRQoL, the last term is the generalized CI of $\varepsilon[39,40]$.

Tobit model was used to estimate Eq. 3 because the EQ-5D utility value is the limited dependent variable and usually has a ceiling effect (a great deal of residents had full health) [34]. The partial effects of independent variables were reported.

\section{Horizontal inequity index}

The horizontal inequity index (HI) of HRQoL was measured by deducting the contributions of unavoidable variables from the CI of HRQoL [42-44]. In this study, the HI of HRQoL was obtained by removing the contributions of unavoidable variables (such as gender and age) from the overall CI of HRQoL. A positive (negative) HI of HRQoL indicated the prorich (pro-poor) inequity. All analyses were performed in Stata version 13.0.

\section{Ethics}

The ethics approval was obtained by the Ethics Committee of Xi'an Jiaotong University Health Science Center (approval number: 2015-644). Informed consent was obtained and the data was anonymized when analyzed.

\section{Results}

\section{Matching performance}

Table 2 showed the basic characteristics of the independent variables. It was obvious that there was significant difference on any social-demographic characteristic (except commercial medical insurance between UEBMI and URBMI) between UEBMI and URBMI, UEBMI and NRCMS and URBMI and NRCMS respectively.

The multivariate $\mathrm{L}_{1}$ statistics were reported in Table 3. After matching, $\mathrm{L}_{1}$ between UEBMI and URBMI, UEBMI and NRCMS and URBMI and NRCMS were all actually close to zero, which were much lower than that before matching $(0.507,0.709$ and 0.533 respectively). Table 4 showed there was no statistical difference on any characteristic between UEBMI and URBMI, UEBMI and NRCMS and URBMI and NRCMS $(P>0.10)$, which indicated good matching performances and thus different groups became more comparable.
Three new databases generated by the CEM method were applied to study the health equity. The first database contained 4558 UEBMI insured residents and 2244 URBMI enrollees, the second one contained 4874 UEBMI insured residents and 29,295 NRCMS enrollees, whilst the third one contained 2426 URBMI insured residents and 34,538 NRCMS enrollees.

\section{Description of EQ-5D dimensions}

The utility value of each dimension and the mean utility value were presented in Table 5 . The results of the matched sample showed the mean utility value were $0.9589[95 \%$ CI $(0.9553,0.9626)]$ and 0.9449 [95\% CI $(0.9387,0.9511)]$ in UEBMI and URBMI, 0.9579 [95\% CI $(0.9543,0.9614)]$ and 0.9473 [95\% CI $(0.9457,0.9488)]$ in UEBMI and NRCMS and 0.9505 [95\% CI $(0.9450,0.9559)]$ and 0.9605 [95\% CI (0.9592, 0.9619)] in URBMI and NRCMS respectively. The differences of mean utility scores between UEBMI and URBMI, UEBMI and NRCMS and URBMI and NRCMS were all significant.

\section{Concentration index and decomposition Concentration index}

Table 6 showed CIs of the 5 dimensions were all negative but the CIs of mean EQ-5D utility scores were all positive, suggesting that health issues were relatively significant among the poorer groups, however, the relatively higher EQ-5D utility scores were relatively significant among the richer groups. In other words, there tended to be less health problems and better HRQoL for the rich insured respondents than that of the poor counterparts covered by UEBMI, URBMI and NRCMS in Shaanxi province [45]. The CIs of overall utility scores were 0.0087 [95\% CI $(0.0065,0.0110)]$ and 0.0083 [95\% CI $(0.0050$, $0.0118)]$ in UEBMI and URBMI, $0.0074 \quad[95 \% \mathrm{CI}$ $(0.0053,0.0096)]$ and 0.0117 [95\% CI $(0.0108,0.0127)$ ] in UEBMI and NRCMS and 0.0084 [95\% CI (0.0076, 0.0092)] and 0.0107 [95\% CI $(0.0099,0.0116)]$ in URBMI and NRCMS respectively.

\section{Decomposition of inequity of $H R Q O L$}

Table 7 presented the decomposition of CIs of the overall utility scores. The estimated partial effects of each related factor of health inequality was calculated based upon the Tobit model. Contribution to the inequality of the overall utility score and the proportion of contribution in the overall CIs were reported.

A positive marginal effect, such as education in UEBMI and URBMI indicated a higher educational level was significantly associated with better HRQoL, 


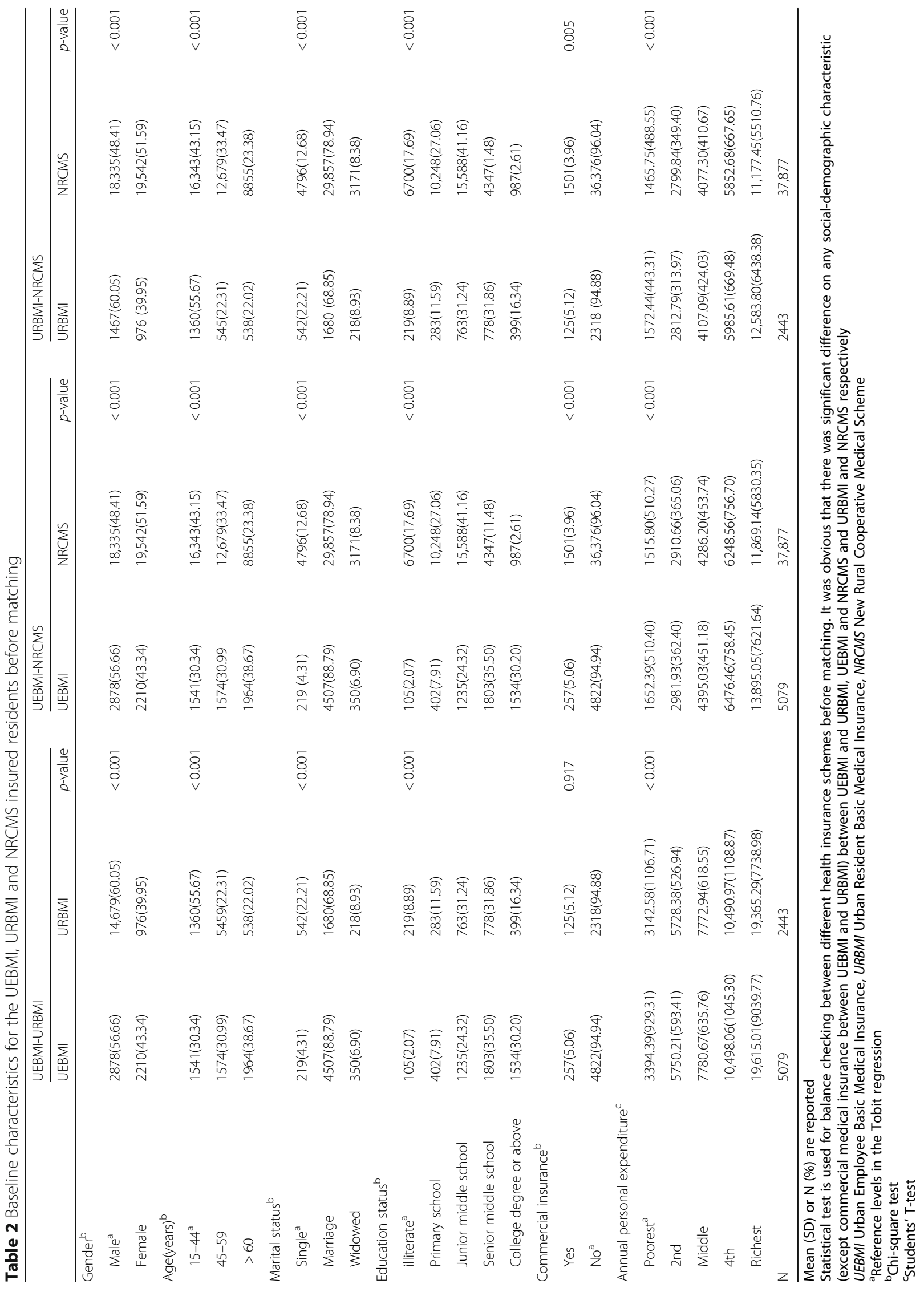


Table 3 The $L_{1}$ measure of imbalance before and after Coarsened Exact Matching

\begin{tabular}{|c|c|c|c|c|c|c|}
\hline & UEBMI-URBMI & & UEBMI-NRCMS & & URBMI-NRCMS & \\
\hline & Before Matching & After Matching & Before Matching & After Matching & Before Matching & After Matching \\
\hline & $\mathrm{L}_{1}($ mean $)$ & $\mathrm{L}_{1}($ mean $)$ & $L_{1}($ mean $)$ & $\mathrm{L}_{1}($ mean $)$ & $\mathrm{L}_{1}($ mean $)$ & $\mathrm{L}_{1}($ mean $)$ \\
\hline Gender & $\begin{array}{l}0.167 \\
(0.167)\end{array}$ & $\begin{array}{l}2.0 \mathrm{e}-15 \\
(-1.4 \mathrm{e}-15)\end{array}$ & $\begin{array}{l}0.083 \\
(0.083)\end{array}$ & $\begin{array}{l}1.6 \mathrm{e}-14 \\
(-1.0 \mathrm{e}-14)\end{array}$ & $\begin{array}{l}0.084 \\
(-0.084)\end{array}$ & $\begin{array}{l}3.4 e-14 \\
(1.7 e-14)\end{array}$ \\
\hline Age & $\begin{array}{l}0.253 \\
(0.419)\end{array}$ & $\begin{array}{l}1.1 e-15 \\
(-6.2 e-15)\end{array}$ & $\begin{array}{l}0.153 \\
(0.280)\end{array}$ & $\begin{array}{l}1.4 \mathrm{e}-14 \\
(-1.1 \mathrm{e}-13)\end{array}$ & $\begin{array}{l}0.125 \\
(-0.139)\end{array}$ & $\begin{array}{l}3.4 \mathrm{e}-14 \\
(-9.1 \mathrm{e}-14)\end{array}$ \\
\hline Marital status & $\begin{array}{l}0.199 \\
(0.169)\end{array}$ & $\begin{array}{l}2.5 e-16 \\
(-2.7 e-15)\end{array}$ & $\begin{array}{l}0.099 \\
(0.069)\end{array}$ & $\begin{array}{l}5.3 e-15 \\
(-7.1 e-14)\end{array}$ & $\begin{array}{l}0.101 \\
(-0.091)\end{array}$ & $\begin{array}{l}1.1 e-14 \\
(-6.5 e-14)\end{array}$ \\
\hline Education status & $\begin{array}{l}0.175 \\
(0.488)\end{array}$ & $\begin{array}{l}7.7 e-16 \\
(-2.7 e-15)\end{array}$ & $\begin{array}{l}0.516 \\
(1.296)\end{array}$ & $\begin{array}{l}1.2 e-14 \\
(3.1 e-15)\end{array}$ & $\begin{array}{l}0.341 \\
(0.808)\end{array}$ & $\begin{array}{l}2.6 e-14 \\
(5.5 e-14)\end{array}$ \\
\hline Commercial insurance & $\begin{array}{l}0.001 \\
(-0.001)\end{array}$ & $\begin{array}{l}3.5 e-16 \\
(-2.4 e-17)\end{array}$ & $\begin{array}{l}0.011 \\
(0.011)\end{array}$ & $\begin{array}{l}1.4 \mathrm{e}-15 \\
(-1.1 \mathrm{e}-15)\end{array}$ & $\begin{array}{l}0.012 \\
(0.012)\end{array}$ & $\begin{array}{l}7.9 e-15 \\
(-3.1 e-15)\end{array}$ \\
\hline Annual personal expenditure & $\begin{array}{l}0.139 \\
(0.465)\end{array}$ & $\begin{array}{l}6.4 e-16 \\
(-1.3 e-15)\end{array}$ & $\begin{array}{l}0.451 \\
(1.395)\end{array}$ & $\begin{array}{l}1.2 e-14 \\
(-2.0 e-13)\end{array}$ & $\begin{array}{l}0.331 \\
(1.041)\end{array}$ & $\begin{array}{l}3.5 e-14 \\
(-1.4 e-13)\end{array}$ \\
\hline Multivariate $L_{1}$ & 0.507 & $2.751 e-16$ & 0.709 & $9.850 e-15$ & 0.533 & $3.086 \mathrm{e}-14$ \\
\hline N & 7522 & 6802 & 42,956 & 34,169 & 40,320 & 36,928 \\
\hline
\end{tabular}

$\mathrm{L}_{1}$ reported the $L_{1 j}$ measure, which is $L_{1}$ computed for the $j_{\text {th }}$ variable separated. The mean was labeled in parentheses reported the difference in means

whilst a negative marginal effect, such as age, suggested the overall HRQoL decreased along the ageing population.

A positive (negative) contribution represented the variable raised (reduced) the pro-rich inequality (Liu et al., 2014). It can be seen immediately that majority of the HRQoL inequality were attributable to age, educational and economic statuses by defining the contributions as a proportion of each variable. Take the UEBMI and NRCMS for example, for the insured residents of UEBMI, we found that age, educational and economic statuses had the largest (52.15\%), second largest (19.88\%) and third largest (19.78\%) contributions to explain the inequality of HRQoL. For the insured residents of NRCMS, age, economic and educational statuses had the largest (49.56\%), second largest (24.53\%) and third largest (16.78\%) contributions to explain the inequality of HRQoL.

\section{Horizontal inequity index}

Table 7 showed the HI of EQ-5D utility score were 0.0036 and 0.0045 in UEBMI and URBMI, 0.0035 and 0.0058 in UEBMI and NRCMS and 0.0053 and 0.0052 in URBMI and NRCMS respectively.

\section{Discussions}

We compared the equity of HRQoL of residents under any two of the schemes. The findings revealed that the insured residents of UEBMI reported higher HRQoL than that of URBMI and NRCMS. Furthermore, URBMI and NRCMS had higher pro-rich health inequity than that of UEBMI. Age, educational and economic statuses were key factors to explain the poor-rich inequity in HRQoL.

The first aim was to compare the effects of UEBMI, URBMI and NRCMS on HRQoL. The descriptive results of the mean EQ-5D utility score significantly suggested that compared with the UEBMI, the insured residents of URBMI and NRCMS had worse HRQoL, and health outcomes for the URBMI insured were the worst. To some extent, health service utilization could be one of the potential reasons, as the health status may be improved upon utilization. In Shaanxi Province, the annual hospitalization rates of UEBMI, NRCMS and URBMI were $14.66 \%, 9.95 \%$ and $9.56 \%$ respectively, and the outpatient visit rations within 2 weeks of UEBMI, NRCMS and URBMI were $12.12 \%, 12.89 \%$ and $11.67 \%$ respectively in 2013 . Moreover, the percentages of non-hospitalized who should have been hospitalized of UEBMI, NRCMS and URBMI were $19.15 \%, 19.09 \%$ and $26.79 \%$ respectively and the percentages of non-visited who should have been visited of UEBMI, NRCMS and URBMI were $17.47 \%$, $22.79 \%$ and $24.62 \%$ respectively.

The second aim was to compare the effects of UEBMI, URBMI and NRCMS on the equity of HRQoL. Based on the CEM matched samples, the positive CIs revealed that the rich people reported better HRQoL than the poor, which was consistent with most other previous research [46]. Moreover, comparing the CIs among three basic health insurance schemes, the results showed the pro-rich health inequality was much higher for the rural scheme than that for the urban ones. Since few related studies compared the effects of different health insurance schemes on the inequality of HRQoL, we could not 


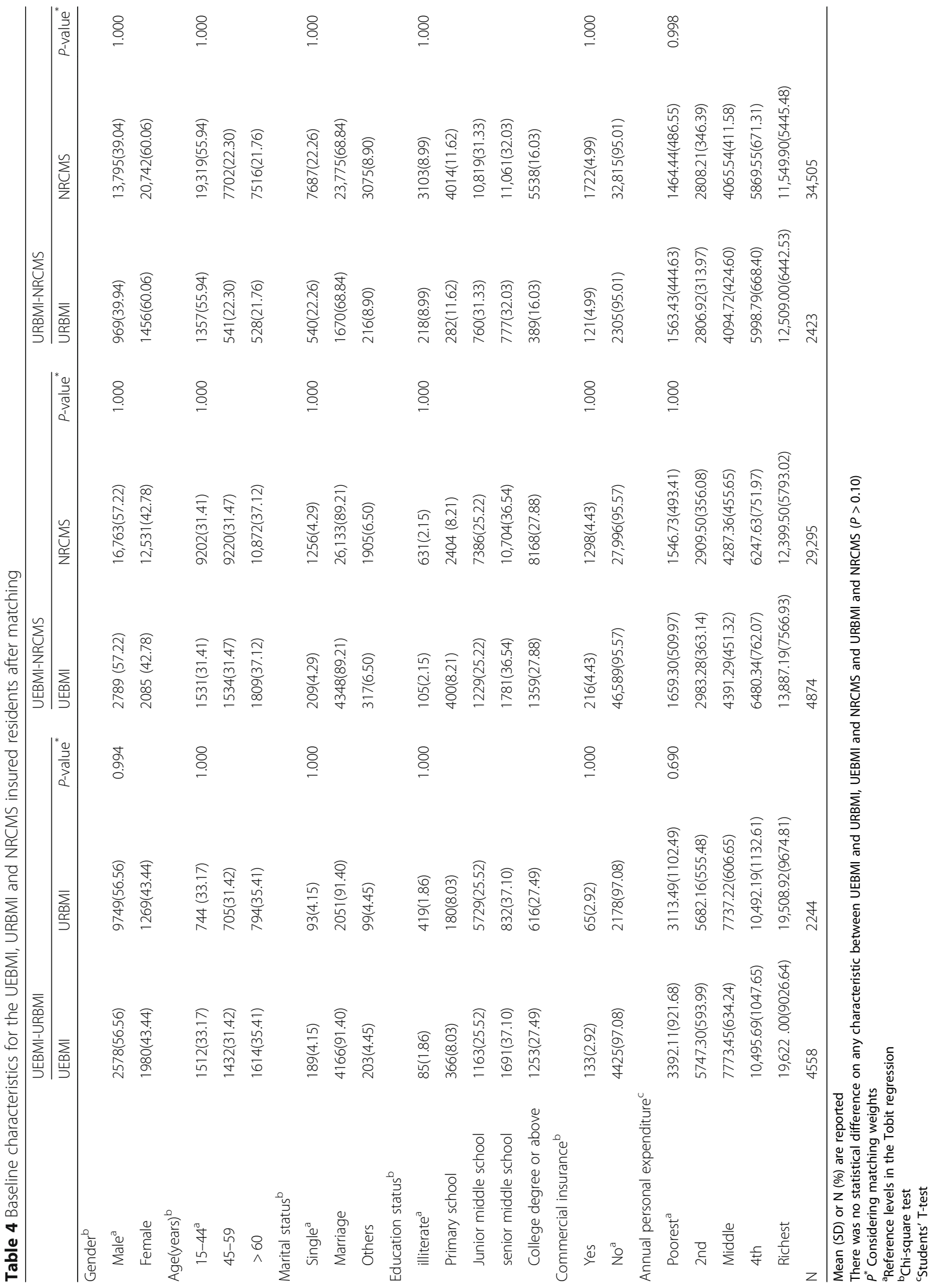


Table 5 Mean and 95\% confidence interval (Cl) of the EQ-5D scores

\begin{tabular}{|c|c|c|c|c|c|c|}
\hline \multirow{3}{*}{ 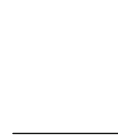 } & \multicolumn{2}{|l|}{ UEBMI-URBMI } & \multicolumn{2}{|l|}{ UEBMI-NRCMS } & \multicolumn{2}{|l|}{ URBMI-NRCMS } \\
\hline & UEBMI & URBMI & UEBMI & NRCMS & URBMI & NRCMS \\
\hline & Mean $(95 \% \mathrm{Cl})$ & Mean $(95 \% \mathrm{Cl})$ & Mean $(95 \% \mathrm{Cl})$ & Mean $(95 \% \mathrm{Cl})$ & Mean $(95 \% \mathrm{Cl})$ & Mean $(95 \% \mathrm{Cl})$ \\
\hline Mobility & $\begin{array}{l}-0.0074 \\
(-0.0083,-0.0065)\end{array}$ & $\begin{array}{l}-0.0082 \\
(-0.0095,-0.0068)\end{array}$ & $\begin{array}{l}-0.0076 \\
(-0.0085,-0.0067)\end{array}$ & $\begin{array}{l}-0.0089 \\
(-0.0082,-0.0085)\end{array}$ & $\begin{array}{l}-0.0084 \\
(-0.0096,-0.0072)\end{array}$ & $\begin{array}{l}-0.0064 \\
(-0.0067,-0.0061)\end{array}$ \\
\hline Selfcare & $\begin{array}{l}-0.0046 \\
(-0.0053,-0.0038)\end{array}$ & $\begin{array}{l}-0.0055 \\
(-0.0066,-0.0043)\end{array}$ & $\begin{array}{l}-0.0047 \\
(-0.0054,-0.0040)\end{array}$ & $\begin{array}{l}-0.0056 \\
(-0.0059,-0.0053)\end{array}$ & $\begin{array}{l}-0.0053 \\
(-0.0064,-0.0043)\end{array}$ & $\begin{array}{l}-0.0042 \\
(-0.0045,-0.0040)\end{array}$ \\
\hline Activity & $\begin{array}{l}-0.0051 \\
(-0.0059,-0.0044)\end{array}$ & $\begin{array}{l}-0.0082 \\
(-0.0096,-0.0068)\end{array}$ & $\begin{array}{l}-0.0053 \\
(-0.0061,-0.0046)\end{array}$ & $\begin{array}{l}-0.0067 \\
(-0.0071,-0.0064)\end{array}$ & $\begin{array}{l}-0.0067 \\
(-0.0078,-0.0055)\end{array}$ & $\begin{array}{l}-0.0051 \\
(-0.0053,-0.0048)\end{array}$ \\
\hline Pain & $\begin{array}{l}-0.0120 \\
(-0.0130,-0.0110)\end{array}$ & $\begin{array}{l}-0.0142 \\
(-0.0157,-0.0125)\end{array}$ & $\begin{array}{l}-0.0123 \\
(-0.0133,-0.0113)\end{array}$ & $\begin{array}{l}-0.0158 \\
(-0.0163,-0.0154)\end{array}$ & $\begin{array}{l}-0.0138 \\
(-0.0153,-0.0123)\end{array}$ & $\begin{array}{l}-0.0117 \\
(-0.0120,-0.0113)\end{array}$ \\
\hline Anxiety & $\begin{array}{l}-0.0053 \\
(-0.0060,-0.0047)\end{array}$ & $\begin{array}{l}-0.0107 \\
(-0.0122,-0.0093)\end{array}$ & $\begin{array}{l}-0.0054 \\
(-0.0060,-0.0047)\end{array}$ & $\begin{array}{l}-0.0077 \\
(-0.0080,-0.0074)\end{array}$ & $\begin{array}{l}-0.0080 \\
(-0.0091,-0.0067)\end{array}$ & $\begin{array}{l}-0.0062 \\
(-0.0064,-0.0059)\end{array}$ \\
\hline EQ5D & $\begin{array}{l}0.9589 \\
(0.9553,0.9626)\end{array}$ & $\begin{array}{l}0.9449 \\
(0.9387,0.9511)\end{array}$ & $\begin{array}{l}0.9579 \\
(0.9543,0.9614)\end{array}$ & $\begin{array}{l}0.9473 \\
(0.9457,0.9488)\end{array}$ & $\begin{array}{l}0.9505 \\
(0.9450,0.9559)\end{array}$ & $\begin{array}{l}0.9605 \\
(0.9592,0.9619)\end{array}$ \\
\hline
\end{tabular}

Differences of mean EQ5D utilities across the three basic health insurances were significant based on the Mann-Whitney $U$ test; The difference across URBMI and NRCMS was not statistically significant

compare this finding with other previous literature. However, theoretically, the goal of developing the health insurance was to protect households from financial catastrophe, and further improve the health service utilization, thus promoting health status by the benefit package design. Therefore, the differences of health inequality between rural and urban insured residents seemed alarming. To some extent, the fragmented benefit package designs could be responsible for the health inequalities among the UEBMI, URBMI and NRCMS. Take the benefit package designs of UEBMI and NRCMS for example. Firstly, UEBMI stipulated higher financing support than NRCMS. The insured residents of UEBMI is financed both by employers and employees, of which $6 \%$ of total salaries was supported by the employer and $2 \%$ of individual salary was financed by the employee.
Whilst the average per capital financing support of NRCMS was RMB 365 (US\$ 58.87) in 2013 (CNBS, 2014). Secondly, UEBMI stipulated higher actual reimbursement ratio than that of NRCMS $(64.84 \%$ and $45.27 \%$ respectively in 2013) [8]. Thirdly, UEBMI included a Social Pooling Account for inpatient care and an Individual Account for outpatient care, whilst NRCMS included a Social Pooling Account for inpatient care and a Household Account for critical outpatient care (e.g. chronic or fatal disease) [36]. All these fragmented benefit package designs may result in the different pro-rich income-related health inequality among different schemes.

The third aim was to compare the HIs of UEBMI, URBMI and NRCMS. The positives HIs revealed that controlling the unavoidable characteristics of HRQoL,

Table 6 Concentration index of the scores of EQ-5D and each of its dimension

\begin{tabular}{|c|c|c|c|c|c|c|}
\hline & \multicolumn{2}{|l|}{ UEBMI-URBMI } & \multicolumn{2}{|l|}{ UEBMI-NRCMS } & \multicolumn{2}{|l|}{ URBMI-NRCMS } \\
\hline & UEBMI & URBMI & UEBMI & NRCMS & URBMI & NRCMS \\
\hline & Mean $(95 \% \mathrm{Cl})$ & Mean $(95 \% \mathrm{Cl})$ & Mean $(95 \% \mathrm{Cl})$ & Mean $(95 \% \mathrm{Cl})$ & Mean $(95 \% \mathrm{Cl})$ & Mean $(95 \% \mathrm{Cl})$ \\
\hline Mobility & $\begin{array}{l}-0.2758^{* * *} \\
(-0.3448,-0.2067)\end{array}$ & $\begin{array}{l}-0.3006^{* * *} \\
(-0.3954,-0.2058)\end{array}$ & $\begin{array}{l}-0.2474^{* * *} \\
(-0.3137,-0.1811)\end{array}$ & $\begin{array}{l}-0.1989^{* * *} \\
(-0.2209,-0.1769)\end{array}$ & $\begin{array}{l}-0.2301^{* * *} \\
(-0.0336,-0.1466)\end{array}$ & $\begin{array}{l}-0.2316^{* * *} \\
(-0.2548,-0.2084)\end{array}$ \\
\hline Selfcare & $\begin{array}{l}-0.3078^{* * *} \\
(-0.4011,-0.2144)\end{array}$ & $\begin{array}{l}-0.2532^{* * *} \\
(-0.3722,-0.1342)\end{array}$ & $\begin{array}{l}-0.2614^{* * *} \\
(-0.3504,-0.1725)\end{array}$ & $\begin{array}{l}-0.2318^{* * *} \\
(-0.2622,-0.2013)\end{array}$ & $\begin{array}{l}-0.1942^{* *} \\
(-0.3091,-0.0079)\end{array}$ & $\begin{array}{l}-0.2611^{* * *} \\
(-0.2910,-0.2312)\end{array}$ \\
\hline Activity & $\begin{array}{l}-0.2989^{* * *} \\
(-0.3822,-0.2155)\end{array}$ & $\begin{array}{l}-0.0469 \\
(-0.1446,-0.0507)\end{array}$ & $\begin{array}{l}-0.2448^{* * *} \\
(-0.3233,-0.1663)\end{array}$ & $\begin{array}{l}-0.1663^{* * *} \\
(-0.1908,-0.1418)\end{array}$ & $\begin{array}{l}-0.2070^{* * *} \\
(-0.3050,-0.1091)\end{array}$ & $\begin{array}{l}-0.2259^{* * *} \\
(-0.2516,-0.2001)\end{array}$ \\
\hline Pain & $\begin{array}{l}-0.1450^{* * *} \\
(-0.1942,-0.0956)\end{array}$ & $\begin{array}{l}-0.0812^{* *} \\
(-0.1439,-0.0185)\end{array}$ & $\begin{array}{l}-0.1104^{* * *} \\
(-0.1571,-0.0638)\end{array}$ & $\begin{array}{l}-0.0463^{* * *} \\
(-0.0593,-0.0334)\end{array}$ & $\begin{array}{l}-0.1288^{* * *} \\
(-0.1917,0.0659)\end{array}$ & $\begin{array}{l}-0.1559^{* * *} \\
(-0.1714,-0.1403)\end{array}$ \\
\hline Anxiety & $\begin{array}{l}-0.1137^{* *} \\
(-0.1868,-0.0406)\end{array}$ & $\begin{array}{l}-0.0112 \\
(-0.0891,0.0668)\end{array}$ & $\begin{array}{l}-0.0921^{* *} \\
(-0.1619,-0.0224)\end{array}$ & $\begin{array}{l}0.0482^{* * *} \\
(0.0290,0.0675)\end{array}$ & $\begin{array}{l}-0.1678^{* * *} \\
(-0.2490,-0.0865)\end{array}$ & $\begin{array}{l}-0.1274^{* * *} \\
(-0.1487,-0.1060)\end{array}$ \\
\hline EQ5D & $\begin{array}{l}0.0087^{* * *} \\
(0.0065,0.0110)\end{array}$ & $\begin{array}{l}0.0083^{* * *} \\
(0.0050,0.0118)\end{array}$ & $\begin{array}{l}0.0074^{* * *} \\
(0.0053,0.0096)\end{array}$ & $\begin{array}{l}0.0117^{* * *} \\
(0.0108,0.0127)\end{array}$ & $\begin{array}{l}0.0084^{* * *} \\
(0.0076,0.0092)\end{array}$ & $\begin{array}{l}0.0107^{* * *} \\
(0.0099,0.0116)\end{array}$ \\
\hline
\end{tabular}

${ }^{*} P<0.05 ;{ }^{* *} P<0.01 i^{* * *} P<0.001$;Differences of Concentration indexes of EQ5D utilities across UEBMI and NRCMS and URBMI and NRCMS were significant based on the Students' T-test; Difference across UEBMI and URBMI was not significant 
Table 7 Decomposition of concentration index for UEBMI, URBMI and NRCMS

\begin{tabular}{|c|c|c|c|c|c|c|c|c|c|c|c|c|}
\hline & \multicolumn{4}{|c|}{ UEBMI- URBMI } & \multicolumn{4}{|c|}{ UEBMI-NRCMS } & \multicolumn{4}{|c|}{ URBMI-NRCMS } \\
\hline & \multicolumn{2}{|l|}{ UEBMI } & \multicolumn{2}{|l|}{ URBMI } & \multicolumn{2}{|c|}{ UEBMI } & \multicolumn{2}{|l|}{ NRCMS } & \multicolumn{2}{|c|}{ URBMI } & \multicolumn{2}{|l|}{ NRCMS } \\
\hline & $d y / d x$ & con (\%) & $d y / d x$ & con (\%) & $d y / d x$ & con $(\%)$ & $d y / d x$ & con (\%) & $d y / d x$ & con (\%) & $d y / d x$ & con (\%) \\
\hline Gender(Female) & -0.0019 & $\begin{array}{l}0.0000 \\
(0.53)\end{array}$ & -0.0052 & $\begin{array}{l}0.0000 \\
(0.41)\end{array}$ & -0.0028 & $\begin{array}{l}0.0001 \\
(0.74)\end{array}$ & $0.0055^{* * * *}$ & $\begin{array}{l}-0.0001 \\
(-0.71)\end{array}$ & -0.0061 & $\begin{array}{l}0.0000 \\
(0.29)\end{array}$ & $0.0037^{* *}$ & $\begin{array}{l}0.0000 \\
(-0.07)\end{array}$ \\
\hline $45-59$ & $-0.0168^{* * *}$ & $\begin{array}{l}-0.0003 \\
(-3.63)\end{array}$ & $-0.0226^{* * *}$ & $\begin{array}{l}0.0004 \\
(5.16)\end{array}$ & $-0.0150^{* *}$ & $\begin{array}{l}-0.0003 \\
(-3.70)\end{array}$ & $-0.0207^{* * *}$ & $\begin{array}{l}-0.0002 \\
(-1.94)\end{array}$ & $-0.0204^{* *}$ & $\begin{array}{l}0.0004 \\
(5.07)\end{array}$ & $-0.0214^{* * *}$ & $\begin{array}{l}0.0001 \\
(0.48)\end{array}$ \\
\hline 60 or above & $-0.0607^{* * *}$ & $\begin{array}{l}0.0051 \\
(59.06)\end{array}$ & $-0.0662^{* * *}$ & $\begin{array}{l}0.0038 \\
(45.49)\end{array}$ & $-0.0570^{* * * *}$ & $\begin{array}{l}0.0041 \\
(55.85)\end{array}$ & $-0.0690^{* * *}$ & $\begin{array}{l}0.0060 \\
(51.50)\end{array}$ & $-0.0576^{* * *}$ & $\begin{array}{l}0.0028 \\
(33.88)\end{array}$ & $-0.0765^{* * *}$ & $\begin{array}{l}0.0053 \\
(49.47)\end{array}$ \\
\hline Marriage & 0.0059 & $\begin{array}{l}0.0001 \\
(0.96)\end{array}$ & -0.0053 & $\begin{array}{l}0.0000 \\
(0.47)\end{array}$ & 0.0039 & $\begin{array}{l}0.0001 \\
(0.70)\end{array}$ & -0.0044 & $\begin{array}{l}0.0000 \\
(0.02)\end{array}$ & -0.0021 & $\begin{array}{l}0.0000 \\
(0.06)\end{array}$ & -0.0009 & $\begin{array}{l}0.0000 \\
(-0.03)\end{array}$ \\
\hline Others & $-0.0309^{* *}$ & $\begin{array}{l}0.0006 \\
(6.72)\end{array}$ & $-0.0515^{* * *}$ & $\begin{array}{l}0.0014 \\
(16.64)\end{array}$ & $-0.0230^{*}$ & $\begin{array}{l}0.0004 \\
(5.19)\end{array}$ & $-0.0606^{* * *}$ & $\begin{array}{l}0.0009 \\
(7.93)\end{array}$ & $-0.0425^{* * *}$ & $\begin{array}{l}0.0011 \\
(13.53)\end{array}$ & $-0.0570^{* * *}$ & $\begin{array}{l}0.0010 \\
(9.05)\end{array}$ \\
\hline Primary school & $0.0349^{* *}$ & $\begin{array}{l}-0.0009 \\
(-10.85)\end{array}$ & $0.0502^{* * *}$ & $\begin{array}{l}-0.0013 \\
(-16.22)\end{array}$ & $0.0527^{* * * *}$ & $\begin{array}{l}-0.0013 \\
(-17.12)\end{array}$ & $0.0448^{* * *}$ & $\begin{array}{l}-0.0016 \\
(-13.81)\end{array}$ & $0.0666^{* * *}$ & $\begin{array}{l}-0.0015 \\
(-17.40)\end{array}$ & $0.0374^{* * *}$ & $\begin{array}{l}-0.0006 \\
(-5.49)\end{array}$ \\
\hline $\begin{array}{l}\text { Junior middle } \\
\text { school }\end{array}$ & $0.0497^{* * *}$ & $\begin{array}{l}-0.0021 \\
(-24.65)\end{array}$ & $0.0772^{* * *}$ & $\begin{array}{l}-0.0020 \\
(-23.61)\end{array}$ & $0.0735^{* * *}$ & $\begin{array}{l}-0.0034 \\
(-45.65)\end{array}$ & $0.0544^{* * *}$ & $\begin{array}{l}0.0018 \\
(15.33)\end{array}$ & $0.0967^{* * *}$ & $\begin{array}{l}-0.0018 \\
(-21.12)\end{array}$ & $0.0487^{* * *}$ & $\begin{array}{l}0.0013 \\
(12.36)\end{array}$ \\
\hline $\begin{array}{l}\text { Senior middle } \\
\text { school }\end{array}$ & $0.0506^{* * *}$ & $\begin{array}{l}-0.0002 \\
(-2.50)\end{array}$ & $0.0814^{* * *}$ & $\begin{array}{l}0.0031 \\
(36.91)\end{array}$ & $0.0748^{* * *}$ & $\begin{array}{l}-0.0009 \\
(-12.18)\end{array}$ & $0.0550^{* * *}$ & $\begin{array}{l}0.0011 \\
(9.57)\end{array}$ & $0.1043^{* * *}$ & $\begin{array}{l}0.0031 \\
(37.30)\end{array}$ & $0.0494^{* * *}$ & $\begin{array}{l}0.0010 \\
(9.76)\end{array}$ \\
\hline $\begin{array}{l}\text { College degree } \\
\text { or above }\end{array}$ & $0.0565^{* * *}$ & $\begin{array}{l}0.0048 \\
(54.72)\end{array}$ & $0.0928^{* * *}$ & $\begin{array}{l}0.0038 \\
(45.43)\end{array}$ & $0.0827^{* * *}$ & $\begin{array}{l}0.0070 \\
(94.83)\end{array}$ & $0.0592^{* * *}$ & $\begin{array}{l}0.0007 \\
(5.69)\end{array}$ & 0.1166 & $\begin{array}{l}0.0045 \\
(54.09)\end{array}$ & $0.0532^{* * *}$ & $\begin{array}{l}0.0005 \\
(5.01)\end{array}$ \\
\hline $\begin{array}{l}\text { Commercial } \\
\text { insurance }\end{array}$ & 0.0050 & $\begin{array}{l}0.0001 \\
(0.59)\end{array}$ & -0.0034 & $\begin{array}{l}0.0001 \\
(1.25)\end{array}$ & 0.0105 & $\begin{array}{l}0.0001 \\
(1.30)\end{array}$ & $0.0066^{* * *}$ & $\begin{array}{l}0.0001 \\
(0.46)\end{array}$ & 0.0096 & $\begin{array}{l}0.0002 \\
(2.33)\end{array}$ & $0.0009^{* * *}$ & $\begin{array}{l}0.0000 \\
(0.10)\end{array}$ \\
\hline 2nd & 0.0015 & $\begin{array}{l}-0.0001 \\
(-1.64)\end{array}$ & $0.0034^{* * *}$ & $\begin{array}{l}-0.0002 \\
(-2.27)\end{array}$ & 0.0181 & $\begin{array}{l}-0.0011 \\
(-15.04)\end{array}$ & $0.0217^{* * *}$ & $\begin{array}{l}-0.0022 \\
(-18.62)\end{array}$ & $0.0081^{* * *}$ & $\begin{array}{l}-0.0007 \\
(-8.11)\end{array}$ & $0.0170^{* * *}$ & $\begin{array}{l}-0.0016 \\
(-14.63)\end{array}$ \\
\hline Middle & 0.0044 & $\begin{array}{l}-0.0001 \\
(-0.65)\end{array}$ & 0.0049 & $\begin{array}{l}0.0002 \\
(2.27)\end{array}$ & 0.0197 & $\begin{array}{l}-0.0017 \\
(-23.32)\end{array}$ & $0.0215^{* * *}$ & $\begin{array}{l}0.0000 \\
(-0.01)\end{array}$ & -0.0020 & $\begin{array}{l}0.0000 \\
(0.00)\end{array}$ & $0.0168^{* * *}$ & $\begin{array}{l}0.0000 \\
(-0.07)\end{array}$ \\
\hline 4th & $0.0091^{* * *}$ & $\begin{array}{l}0.0007 \\
(7.85)\end{array}$ & $-0.0016^{* * *}$ & $\begin{array}{l}-0.0001 \\
(-1.73)\end{array}$ & $0.0227^{*}$ & $\begin{array}{l}-0.0020 \\
(-27.13)\end{array}$ & $0.0172^{* * *}$ & $\begin{array}{l}0.0016 \\
(13.87)\end{array}$ & $0.0039^{* * *}$ & $\begin{array}{l}0.0003 \\
(3.90)\end{array}$ & $0.0127^{* * *}$ & $\begin{array}{l}0.0011 \\
(10.40)\end{array}$ \\
\hline Richest & $0.0051^{* * *}$ & $\begin{array}{l}0.0009 \\
(10.68)\end{array}$ & -0.0034 & $\begin{array}{l}-0.0005 \\
(-5.49)\end{array}$ & $0.0244^{*}$ & $\begin{array}{l}0.0063 \\
(85.27)\end{array}$ & $0.0217^{* * *}$ & $\begin{array}{l}0.0034 \\
(29.29)\end{array}$ & -0.0006 & $\begin{array}{l}-0.0001 \\
(-1.13)\end{array}$ & $0.0143^{* * *}$ & $\begin{array}{l}0.0023 \\
(21.87)\end{array}$ \\
\hline $\mathrm{Cl}$ & 0.0087 & & 0.0083 & & 0.0074 & & 0.0117 & & 0.0084 & & 0.0107 & \\
\hline $\begin{array}{l}\text { Con of health } \\
\text { need }\end{array}$ & 0.0049 & & 0.0042 & & 0.0039 & & 0.0057 & & 0.0033 & & 0.0053 & \\
\hline $\mathrm{HI}$ & 0.0036 & & 0.0045 & & 0.0035 & & 0.0058 & & 0.0053 & & 0.0052 & \\
\hline
\end{tabular}

$\mathrm{dy} / \mathrm{dx}$, the partial effect in Tobit regression model; Con, the contribution of regression to inequality of EQ-5D utility score; \%, the share of contribution index of EQ-5D utility score

the URBMI had marginally higher pro-rich health inequity of HRQoL than that of NRCMS, and both of them had a higher pro-rich health inequity than that of UEBMI. Findings from the decomposition of inequality in HRQoL indicated the HIs were mainly explained by age, educational and economic statuses for both urban and rural insured residents, which was consistent with previous studies analyzing health inequity of the whole population of Shaanxi Province [36]. Therefore, we must consider the contributions of key determinants when formulating health policy interventions, allocating health resources and relieving health inequities. It is crucial to facilitate the health conditions of the aged population and narrow economic and educational gaps between the rich and the poor for both rural and urban insured residents.
There are some limitations should be noted. Firstly, owing to the cross-sectional data, only the association other than the causal inference between basic health insurance schemes and HRQoL was investigated. Secondly, the survey data was drawn from Shaanxi Province. Next, because of the data availability, we could not consider all the unobservable heterogeneities (e.g. URBMI and NRCMS are both voluntary schemes, but UEBMI is a compulsory counterpart) and other mediating factors such as access to healthy food, lifestyle and so forth, which may lead to bias. Additionally, the selfreported information on EQ-5D and healthcare utilization may be subjected to recall bias. Finally, employing the EQ-5D-3 L instrument to measure HRQoL also has some limitations. There exists a 
severe ceiling effect on EQ-5D, especially for the general population [46, 47]. Additionally, a related research indicated that the EQ-5D-3L instrument is not as sensitive as the SF-6D instrument in assessing HRQoL [40]. However, EQ-5D-3L is the only instrument that has been used in such large scale household surveys in China.

\section{Conclusions}

This study has demonstrated the more generous health insurance scheme was generally associated with improved population heath and can reduce health inequity, particularly for the vulnerable groups. Furthermore, the income-related health inequities in HRQoL were mainly explained by age, educational and economic statuses for both rural and urban insured residents. Overall, it can be seen immediately that the basic health insurance schemes had positive impacts on decreasing the inequity in population health, but the effects were relatively limited, especially URBMI and NRCMS. Therefore, our results highlight the need to consolidate all three schemes and achieve the universal health coverage by administrating uniformly, merging funds pooling and consolidating the fragmented benefit packages and so on. Besides, based on the contributing factors which may result in health inequity, more efforts are urged to improve the health condition of the aged population, especially by preventing chronic diseases like hypertension and diabetes. Last, narrowing the economic gap by taking targeted measures in poverty alleviation and relieving educational inequity between the rich and the poor is helpful for improving HRQoL and then reducing prorich health inequity in Shaanxi Province.

\section{Abbreviations}

CEM: Coarsened exact matching; Cl: Concentration Index; EQ-5D: EuroQol 5 dimension; HI: Horizontal inequity index; HRQoL: Health-related quality of life; NHSS: National Health Services Survey; NRCMS: New Rural Cooperative Medical Scheme; RMHC: Rural Mutual Health Care; UEBMI: Urban Employee Basic Medical Insurance; URBMI: Urban Resident Basic Medical Insurance

\section{Acknowledgments \\ The authors are thankful to the Health Department of Shaanxi Province for providing data for analysis.}

\section{Funding}

This study was funded by the Research Program of Shaanxi Soft Science (2015KRM117), Project of Shaanxi Social Science Foundation (2017S024), the National high-level talents special support plan ("thousands of people plan") and Shaanxi provincial youth star of science and technology in 2016. The funding bodies had no role in the design of the study or collection, analysis, and interpretation of data, and they did not contribute to the writing of the manuscript.

\section{Availability of data and materials}

This data was drawn from the 5th National Health Services Survey (NHSS) of Shaanxi Province. They are available from the Shaanxi Health and Family Planning Commission for researchers who meet the criteria for access to confidential data, and are not opened to everyone. Researchers who want to use these data should contact Zhongliang Zhou (zzliang1981@163.com).

\section{Authors' contributions}

MS participated in the study design, data analysis and interpretation, and was the primary person responsible for drafting the manuscript. ZZ contributed to study design, data analysis and revision. YS and XW conceived of the study and participated in data analysis and revision. YX and XF contributed to data analysis and revision. GC participated in revision. All authors read and approved the final manuscript.

\section{Ethics approval and consent to participate}

The ethics approval was obtained by the Ethics Committee of Xi'an Jiaotong University Health Science Center (approval number: 2015-644). Informed consent was obtained and the data was anonymized when analyzed.

\section{Consent for publication}

Not applicable.

\section{Competing interests}

The authors declare that they have no competing interests.

\section{Publisher's Note}

Springer Nature remains neutral with regard to jurisdictional claims in published maps and institutional affiliations.

\section{Author details}

${ }^{1}$ School of Public Policy and Administration, Xi'an Jiaotong University, Xi'an, China. ${ }^{2}$ Division of Clinical Public Health, and Institute of Health Policy Management and Evaluation, Dalla Lana School of Public Health, University of Toronto, Toronto, Canada. ${ }^{3}$ School of Public Health, Health Science Center, Xi'an Jiaotong University, Xi'an, China. ${ }^{4}$ Monash Business School, Monash University, Clayton, Australia.

Received: 25 July 2017 Accepted: 21 February 2018

Published online: 07 March 2018

\section{Reference}

1. Wagstaff A, van Doorslaer E, van der Burg H, Calonge S, Christiansen $T$, Citoni $G$, et al. Equity in the finance of health care: some further international comparisons. Health Econ. 1999;18(3):263-90. https://doi. org/10.1016/S0167-6296(98)00044-7.

2. Guo Y, Shibuya K, Cheng G, Rao K, Lee L, Tang S. Tracking China's health reform. Lancet. 2010;375(9720):1056-8. https://doi.org/10.1016/ S0140-6736(10)60397-2

3. Sun Q, Liu X, Meng Q, Tang S, Yu B, Tolhurst R. Evaluating the financial protection of patients with chronic disease by health insurance in rural China. Int J Equity Health. 2009:8:42. https://doi.org/10.1186/1475-9276-8-42.

4. Yip WC, Hsiao WC, Chen W, Hu S, Ma J, Maynard A. Early appraisal of China's huge and complex health-care reforms. Lancet 2012; 379(9818):833842. https://doi.org/10.1016/S0140-6736 (11)61880-1.

5. Yip W, Hsiao W. China's health care reform: a tentative assessment. China Econ Rev. 2009;20(4):613-9. https://doi.org/10.1016/j.chieco.2009.08.003.

6. Hu S, Tang S, Liu Y, et al. Reform of how health care is paid for in China: challenges and opportunities. Lancet. 2008;372(9652):1846-53.

7. Yip WCM, Hsiao WC, Chen W, et al. Early appraisal of China's huge and complex health-care reforms. Lancet. 2012;379(9818):833-42.

8. CNBS (China National Bureau of Statistics).2014. Statistical bulletin of national economy and social development of the year 2013. http://www.stats.gov.cn.

9. Pan J, Lei X, Liu GG. Health insurance and health status: exploring the causal effect from a policy intervention. Health Econ. 2016;25(11):1389-402.

10. Li X, Lu J, Hu S, et al. The primary health-care system in China[J]. The Lancet. 2017;390(10112):2584-2594. https://doi.org/10.1016/S01406736(17)33109-4.

11. Meng Q, Fang H, Liu X, Yuan B, Xu J. Consolidating the social health insurance schemes in China: towards an equitable and efficient health system. Lancet. 2015;386(10002):1484-92. https://doi.org/10.1016/S0140-6736(15)00342-6.

12. Mclntyre D, Garshong B, Mtei G, et al. Beyond fragmentation and towards universal coverage: insights from Ghana, South Africa and the United Republic of Tanzania. Bull World Health Organ. 2008;86(11):871-6. 
13. Mclntyre D. Pay the piper and call the tune: changing health care financing mechanisms to address public-private health sector mix inequities, The economics of health equity; 2007. p. 176-96.

14. Fu R, Wang $Y$, Bao $H$, et al. Trend of urban-rural disparities in hospital admissions and medical expenditure in China from 2003 to 2011[J]. PLoS One. 2014;9(9):e108571.

15. Yang W. China's new cooperative medical scheme and equity in access to health care: evidence from a longitudinal household survey. Int J Equity Health. 2013;12(1):21

16. Moreno-Serra R, Smith PC. Does progress towards universal health coverage improve population health? Lancet. 2012;380(9845):917-23.

17. Pan J, Lei X, Liu GG. Health insurance and health status: exploring the causal effect from a policy intervention[J]. Health economics. 2016;25(11):1389-1402.

18. Wang H, Yip W, Zhang L, Hsiao WC. The impact of rural mutual health care on health status: evaluation of a social experiment in rural China. Health Econ. 2009;18(S2):S65-82. https://doi.org/10.1002/hec.1465.

19. Pan J, Qin XZ. Does health insurance promote health? Lit. Rev World Econ Paper. 2014;6:60-70. (In Chinese).

20. Chen L, Yip W, Chang MC, et al. The effects of Taiwan's National Health Insurance on access and health status of the elderly. Health Econ. 2007; 16(3):223-42.

21. Lei $X$, Lin W. The new cooperative medical scheme in rural China: does more coverage mean more service and better health? Health Econ. 2009; 18(S2):S25-46. https://doi.org/10.1002/hec.1501.

22. Hu HW, Liu GG. Impact of urban resident basic medical insurance on National Health: effect evaluation and evidence of mechanism. South Chin J Econ. 2012;10:186-99. (In Chinese).

23. lacus SM, King G, Porro G. Multivariate matching methods that are monotonic imbalance bounding. J Am Stat Assoc. 2011;106(493):345-61. https://doi.org/10.1198/jasa.2011.tm09599.

24. lacus SM, King G, Porro G. Causal inference without balance checking: coarsened exact matching. Polit Anal. 2012;20:1-24. https://doi.org/10.1093/pan/mpr013.

25. Liu X, Gao W, Yan H. Measuring and decomposing the inequality of maternal health services utilization in western rural China. BMC Health Serv Res. 2014; 14(1):1. https://doi.org/10.1186/1472-6963-14-102.

26. McGrail KM, van Doorslaer E, Ross NA, Sanmartin C. Income-related health inequalities in Canada and the United States: a decomposition analysis. Am J Public Health. 2009;99:1856-63. https://doi.org/10.2105/AJPH.2007.129361.

27. Lauridsen J, Christiansen T, Gundgaard J, Hakkinen U, Sintonen H. Decomposition of health inequality by determinants and dimensions. Health Econ. 2007;16:97-102. https://doi.org/10.1002/hec.1145.

28. Gao J, Tang SL, Tolhurst R, Rao KQ. Changing access to health services in urban China: implications for equity. Health Policy Plan. 2001;16:302-12. https://doi.org/10.1093/heapol/16.3.302.

29. Richardson J, Mckie J, Bariola E. Multiattribute utility instruments and their use; 2014. p. 341-57.

30. EuroQol Group. EuroQol-a new facility for the measurement of health-related quality of life. Health policy (Amsterdam, Netherlands). 1990;16:199-208. https://doi.org/10.1016/0168-8510(90)90421-9.

31. Gotsadze G, Murphy A, Shengelia N, Zoidze A. Healthcare utilization and expenditures for chronic and acute conditions in Georgia: does benefit package design matter? BMC Health Serv Res. 2015;15 https://doi.org/10.1186/s12913-015-0755-X.

32. Blackwell M, lacus S, King G, Porro G. Cem: coarsened exact matching in Stata. Stata J. 2009;9:524-46.

33. Green MA, Subramanian SV, Vickers D, Dorling D. Internal migration, area effects and health: does where you move to impact upon your health? Soc. Sci. Med. 2015;136:27-34. https://doi.org/10.1016/j.socscimed.2015.05.011.

34. Murphy A, Mahal A, Richardson E, Moran AE. The economic burden of chronic disease care faced by households in Ukraine: a cross-sectional matching study of angina patients. Int J Equity Health. 2013;12(1):1. https://doi.org/10.1186/1475-9276-12-38.

35. Kakwani N, Wagstaff A, VanDoorslaer E. Socioeconomic inequalities in health: measurement, computation, and statistical inference. J Econometrics. 1997;77(1):87-103. https://doi.org/10.1016/S0304-4076(96)01807-6.

36. Zhou Z, Zhu L, Zhou Z, Li Z, Gao J, Chen G. The effects of China's urban basic medical health schemes on the equity of health service utilisation: evidence from Shaanxi Province. Int J Equity Health. 2014; 13(1):1. https://doi.org/10.1186/1475-9276-13-23.
37. Wagstaff $A$. The bounds of the concentration index when the variable of interest is binary, with an application to immunization inequality. Health Econ. 2005;14:429-32. https://doi.org/10.1002/hec.953.

38. Collins $E$, Klein R. Equity and the NHS: self-reported morbidity, access, and primary care. BMJ. 1980;281(6248):1111-5. https://doi.org/10.1136/bmj.281.6248.1111.

39. Wagstaff A, Van Doorslaer E, Paci P. Equity in the finance and delivery of health care: some tentative cross-country comparisons. Oxf Rev Econ Policy. 1989;5(1):89-112.

40. Xu Y, Gao J, Zhou Z, Xue Q, Yang J, Luo H, Li Y, Lai S, Chen G. Measurement and explanation of socioeconomic inequality in catastrophic health care expenditure: evidence from the rural areas of Shaanxi Province. BMC Health Serv Res. 2015;15(1):256. https://doi.org/10.1186/s12913-015-0892-2.

41. Wagstaff A, van Doorslaer E, Watanabe N. On decomposing the causes of health sector inequalities with an application to malnutrition inequalities in Vietnam. J Econometrics. 2003;112:207-23. https://doi.org/10.1016/S03044076(02)00161-6.

42. Brazier JE, Yang Y, Tsuchiya A, et al. A review of studies mapping (or cross walking) non-preference based measures of health to generic preference-based measures. Eur J Health Econ. 2010;11(2):215-25. https://doi.org/10.1007/s10198-009-0168-z.

43. O'Donnell O, Van Doorslaer E, Wagstaff A. 17 decomposition of inequalities in health and health care, The Elgar companion to health economics; 2006. p. 179.

44. Xu K. Analyzing health equity using household survey data: a guide to techniques and their implementation. Bulletin of the World Health Organization. Int. J. Public Health. 2008;86:816.

45. Zhou Z, Fang Y, Zhou Z, et al. Assessing income-related health inequality and horizontal inequity in China. Soc Indic Res. 2016:1-16. https://doi.org/ 10.1007/s11205-015-1221-1.

46. Tan Z, Liang Y, Liu S, Cao W, Tu H, Guo L, Xu Y. Health-related quality of life as measured with EQ-5D among populations with and without specific chronic conditions: a population-based survey in Shaanxi Province, China. PLoS One. 2013;8(7):e65958. https://doi.org/10.1371/journal.pone.0065958.

47. Sun $S$, Chen J, Johannesson M, Kind P, Xu L, Zhang Y, Burstrom K. Population health status in China: EQ-5D results, by age, sex and socioeconomic status, from the National Health Services Survey 2008. Qual Life Res. 2008;20:309-20. https://doi.org/10.1007/s11136-010-9762-x.

\section{Submit your next manuscript to BioMed Central and we will help you at every step:}

- We accept pre-submission inquiries

- Our selector tool helps you to find the most relevant journal

- We provide round the clock customer support

- Convenient online submission

- Thorough peer review

- Inclusion in PubMed and all major indexing services

- Maximum visibility for your research

Submit your manuscript at www.biomedcentral.com/submit
Biomed Central 